\title{
Produção de antígeno viral para o sorodiagnóstico da artrite-encefalite caprina utilizando um teste imunoenzimático (ELISA)
}

\author{
Julianna Alves Torres ${ }^{1}$ \\ Gúbio Soares Campos ${ }^{2}$ \\ Michael Menezes Freitas ${ }^{3}$ \\ Camila Fonseca Lopes Brandão ${ }^{4}$ \\ Silvia Inês Sardi ${ }^{5}$
}

\begin{abstract}
Resumo
O vírus da Artrite-encefalite caprina (CAEV) é um Lentivírus de pequenos ruminantes, que causa uma doença crônica e progressiva, caracterizada por encefalomielite, mastite, pneumonia e artrite. O diagnóstico é baseado na detecção de anticorpos contra o vírus através da Imunodifusão em Gel de Agarose (IDGA), técnica sorológica de referência para CAEV, porém de baixa sensibilidade. O objetivo deste trabalho foi produzir um antígeno a partir da cultura de células de membrana sinovial caprina (MSC) infectadas com a CAEV, para ser utilizado em um teste diagnóstico (ELISA indireto). O antígeno foi obtido de culturas de células de MSC infectadas e posterior tratamento com SDS 0,1\%. Amostras de soros caprinos ( $\mathrm{n}=343$ ) foram utilizadas para detectar a presença de anticorpos para CAEV pelo teste ELISA indireto e a técnica IDGA. Nessas amostras, o teste ELISA detectou 72 (21\%) amostras positivas. Entretanto, o teste IDGA detectou $30(8 \%)$ amostras positivas. O ELISA indireto também detectou precocemente uma soroconversão em 5 animais de um total de 13 controlados periodicamente durante 2 anos. A sensibilidade e a especificidade do teste ELISA com relação a IDGA foi de 73,3\% e 84\% respectivamente. Esse ELISA com o antígeno viral assim produzido mostrou-se efetivo, de baixo custo e sensível para o diagnóstico sorológico de anticorpos para CAEV.
\end{abstract}

Palavras-chave: Artrite-encefalite caprina - Diagnóstico; ELISA.

\section{INTRODUÇÃO}

O vírus da artrite-encefalite caprina $(\mathrm{CAEV})$ pertence à família Retroviridae, gênero Lentivirus. É um patógeno que causa uma doença severa e progressiva em caprinos, determinando importantes perdas econômicas decorrentes da morte de animais jovens, diminuição da produção láctea e perda de peso. As manifestações clínicas dessa doença são encefalomielite, artrite, pneumonia intersticial e mastite (PHELPS; SMITH, 1993; CALLADO; CASTRO; TEIXEIRA, 2001).

A detecção precoce de animais infectados para sua posterior separação e (ou) eliminação

\footnotetext{
${ }^{1}$ Aluna de pós-graduação -Mestrado em Ciência Animal nos Trópicos - UFBA.

E-mail: jalvestorres@globo.com.

${ }^{2}$ Professor Dr. do ICS - Universidade Federal da Bahia

${ }^{3}$ Aluno de pós-graduação - Mestrado em Imunologia - UFBA.

${ }^{4}$ Aluna de pós-graduação - Mestrado em Imunologia - UFBA.

${ }^{5}$ Profa. Dra. Da Escola de Medicina Veterinária - UFBA.

Correspondência para / Correspondence to:

Gúbio Soares Campos

Instituto de Ciências da Saúde -UFBA.

Av. Reitor Miguel Calmon, s/n , $2^{\circ}$ andar - Laboratório de Virologia - Vale do Canela.

40.110-100. Salvador - Bahia - Brasil.

Tel: (71) 3235-0937/ 3378-9050/ 9978-5527.
} 
do rebanho é uma forma prática e eficiente para limitar a disseminação do vírus. A infecção é primariamente detectada pela presença de anticorpos específicos no soro de animais infectados através da imunodifusão em gel de agarose (IDGA), ou testes imunoenzimáticos (ELISA) (HECKERT et al., 1992; SIMARD et al., 2001). O teste ELISA permite processar um grande número de amostras; a sensibilidade e especificidade do teste depende da qualidade do antígeno. De acordo com a Organização Internacional de Epizootias (OIE), a produção de antígenos de qualidade satisfatória tem limitado a aplicação do teste ELISA como rotina para o diagnóstico do CAEV (HARKISS; WATT, 1990).

Heckert e colaboradores (1992) afirmam que os antígenos utilizados em testes diagnósticos, comumente obtidos de culturas celulares infectadas, usam metodologias que implicam a purificação do antígeno viral, o que encarece e dificulta a obtenção de antígeno com possível perda de material. Este artigo descreve um método eficiente e simples para produção de um antígeno derivado de cultura de células para ser utilizado em um teste ELISA indireto no diagnóstico do CAEV.

\section{MATERIAIS E MÉTODOS}

\section{Produção de antígeno viral}

Cultivos de células de MSC, utilizados para replicação viral, foram obtidos a partir do explante das membranas sinoviais da articulação intercarpial (ABREU et al., 1998) de cabritos negativos para CAEV pelo teste de reação em cadeia de polimerase (PCR).

Após 15 a 20 dias de incubação, os explantes e as monocamadas por desagregação celular (Tripsina 1:250 GIBCO)foram subcultivadas para a amplificação das culturas celulares.

Os cultivos de células de MSC foram infectados com CAEV - cepa DECENTE (TIGRE; CAMPOS; SARDI, 2006) e, após o aparecimento do efeito citopático, foram congelados e descongelados (rompimento celular e liberação do vírus), para logo depois o material ser centrifugado a $10000 \mathrm{rpm}$ durante 30 minutos. O pellet de células foi ressuspenso em solução PBS (proporção de 1:10 do volume inicial), para logo ser tratado com SDS. O mesmo procedimento foi realizado com cultivos de células de MSC sem infectar, à exceção do tratamento com SDS.

Tratamento do antígeno viral com Dodecil Sulfato de Sódio (SDS)

$\mathrm{O}$ antígeno viral foi tratado com Dodecil sulfato de sodio (SDS - Sigma Co) a uma concentração final de $0,1 \%(\mathrm{v} / \mathrm{v})$. O tratamento foi realizado durante 10 minutos, em temperatura ambiente, com homogeneizações freqüentes. Posteriormente, o material foi centrifugado a $10000 \mathrm{~g}$ durante 15 minutos a $4^{\circ} \mathrm{C}$. O sobrenadante foi coletado e utilizado como antígeno viral para o teste ELISA.

\section{Titulação do antígeno viral}

Para determinar a diluição de uso do antígeno viral, uma placa de poliestireno de 96 poços (NUNC-MAXISORP TM) foi sensibilizada com diluiçôes seriadas desse antigeno em tampão carbonato-bicarbonato (Na2CO3 1,7g/l, NaHCO3 2,86g/l) 0,05M $\mathrm{pH} 9,6$. A placa sensibilizada foi incubada a $4^{\circ} \mathrm{C}$ toda a noite. Passado esse período, os poços foram lavados 5 vezes com uma solução de PBST 0,05\%, e incubados novamente (com solução de PBS leite 5\% (PBS-L), para fazer o bloqueio de sítios livres reativos), durante 1 hora e 30 min. a $37^{\circ} \mathrm{C}$, Em seguida, a solução PBS-L de bloqueio foi descartada e foram adicionados aos poços soro hiperimune de coelho na diluição de 1:2000 em solução de PBS-L (0,5\%). A placa foi novamente incubada por 1 hora e $30 \mathrm{~min}$. a $37^{\circ} \mathrm{C}$. Passado esse período, os poços foram lavados, como citado anteriormente, e incubados com anticorpo anti-IgG de coelho (1:5000), marcado com peroxidase (Sigma), durante 1 hora a $37^{\circ} \mathrm{C}$. A revelação da reação foi feita com o substrato de 3,3', 5,5'-tetramethylbenidine (TMB), em presença de $\mathrm{H}_{2} \mathrm{O}_{2}(10 \mathrm{ml} / 3 \mu \mathrm{L})$ e, após $10 \mathrm{~min}$, foi utilizado o ácido fluorídrico $0,125 \%$, para parar a reação, e realizada a leitura da densidade óptica (D.O.) a $630 \mathrm{~nm}$. A diluição de uso foi estabelecida em 1/50, que corresponde a uma concentração protéica de 
aproximadamente $3 \mu \mathrm{g} /$ poço (método Lowry, BIORAD).

\section{Padrão eletroforético das proteínas virais}

$\mathrm{O}$ antígeno viral utilizado no teste ELISA foi submetido à corrida eletroforética de proteínas virais, utilizando-se a técnica de SDS-PAGE (LAEMMLI, 1970) em gel de gradiente 5-15\% de poliacrilamida.

O peso molecular das proteínas virais foi calculado usando-se o $R f$ (Distância em centímetros de migração da proteína / distância em centímetros da migração do corante Coomassie blue) (GARFIN, 1990).

\section{Animais}

Foram selecionados caprinos $(\mathrm{n}=343)$, machos e fêmeas, com idade entre 1 e 4 anos, das raças Anglonubiana, Saanen, Pardo-alpino e sem raça definida (SRD), sem antecedentes da doença e aparentemente saudáveis. Esses animais provinham de propriedades $(n=14)$ situadas nos municípios de Camaçari, Bomfim de Feira, Feira de Santana, Guanambi, Central, Ipirá, Baixa Grande e Itaberaba, do estado da Bahia (Tabela1).

Foram coletadas amostras de sangue $(\mathrm{n}=343)$ por punção da veia jugular para obtenção de soro. Posteriormente, cada soro foi centrifugado a $2000 \mathrm{rpm}$ durante 5 minutos, e transferido para um tubo tipo eppendorff para ser congelado $\left(-20^{\circ} \mathrm{C}\right)$ até o momento do seu uso. Esses soros foram submetidos às técnicas de Imunodifusão em gel de agarose (IDGA) e ELISA indireto para determinação de anticorpos para CAEV.

Deteç̧ão sorológica de anticorpos para CAEV Imunodifusão em Gel de Agarose (IDGA)

O teste sorológico de IDGA foi realizado com um kit de uso comercial (Biovetech ${ }^{\circledR}$ ), seguindo-se as orientações do fabricante. Esse teste utiliza um antígeno específico do CAEV, a proteína do capsídeo ( $\mathrm{p} 28)$.

A primeira leitura foi feita às 24 horas, e, após 48 horas, realizou-se a leitura confirmatória, para verificar a presença e a identidade das linhas de precipitação (continuidade ou não de linhas entre soro reagente e soro teste).

\section{ELISA indireto}

O teste ELISA indireto utilizado foi previamente descrito por Schalie e colaboradores (1994), com algumas modificaçōes. A placa de poliestireno de 96 poços (NUNC-MAXISORP TM) foi sensibilizada com o antigeno viral tratado com SDS (3,0 $\mu \mathrm{g} / 100 \mu \mathrm{L}$ (poço) (fileiras ímpares) em tampão carbonato-bicarbonato $\mathrm{pH}$ 9,6, e com células de MSC sem infectar, também na concentração protéica de $3,0 \mu \mathrm{g} / 100 \mu \mathrm{L}$ (poço) (fileiras pares). A placa foi incubada toda a noite a $4^{\circ} \mathrm{C}$. Passado esse período, os poços foram lavados 5 vezes com uma solução de PBST 0,05\%. Posteriormente, foi adicionada uma solução de PBS-L para o bloqueio de sítios livres reativos e incubados novamente, durante 1 hora e 30 min. a $37^{\circ} \mathrm{C}$. Em seguida, foram adicionados aos poços os soros testes dos animais na diluição de 1:100 em solução de PBS-L + $0,3 \%$ Tween 20 (PBS-L $-0,3 \% \mathrm{~T}$ ), e a placa foi incubada toda a noite a $4^{\circ} \mathrm{C}$. Cada soro foi colocado no poço de antígeno viral e no poço de antígeno celular correspondente. Passado esse período, os poços foram lavados, como citado anteriormente, e incubados novamente, durante 1 hora a $37^{\circ} \mathrm{C}$, com anticorpo anti-IgG de cabra conjugado com peroxidase (Sigma), na diluição de 1:15.000 (PBS-L - 0,3\%T). Os poços foram lavados como mencionado anteriormente. A revelação da reação foi feita com o substrato TMB em presença de $\mathrm{H}_{2} \mathrm{O}_{2}(10 \mathrm{ml} / 3 \mu \mathrm{L})$ e, após 30 min, foi utilizado o ácido fluorídrico $0,125 \%$ para parar a reação e realizada a leitura da densidade óptica (D.O.) a $630 \mathrm{~nm}$.

O programa Med Calc calculou o cut-off ou valor de corte, utilizando o método de curva $R O C$. Um valor igual ou maior a 0,209 , resultante da diferença de densidade óptica entre antígeno viral e antígeno celular foi considerado como positivo.

Soro positivo = D.O.soro células de MSC infectadas - D.O. soro células de MSC sem infectar $\geq 0,209$.

Detecção precoce de anticorpos pelo método de ELISA indireto

Caprinos ( $\mathrm{n}=13)$ de um rebanho do município de Feira de Santana (BA) foram acompanhados sorologicamente pelos testes 
IDGA e ELISA por um período de dois anos, sendo realizadas até 3 colheitas de soro, em intervalos de 10 e 11 meses do mesmo animal.

\section{Análise estatística}

O teste Qui-quadrado (SPSS13.0 versão Windows) foi utilizado para avaliar a correlação, e o índice kappa foi usado para analisar a concordância entre as técnicas ELISA indireto e a técnica de referência IDGA. (THRUSFIELD, 1997).

\section{RESULTADOS}

\section{Padrão eletroforético das proteínas virais}

$\mathrm{Na}$ Figura 1, observa-se o padrão eletroforético das proteínas virais de CAEV. O vírus concentrado e ultracentrifugado - Linha 2 (FONTES et al., 2005) - mostra um padrão eletroforético de proteínas com pesos moleculares (PM) aproximados entre 97 e 30 $\mathrm{Kd}$. Dessas, deve-se destacar o grupo de proteínas com PM de 28, 34, 46 e $55 \mathrm{Kd}$, que são os de maior atividade antigênica. Ao comparar esse padrão com o perfil protéico das MSC infectadas com CAEV, mostra-se que esse último tem um perfil similar, mas com uma massa protéica maior (Linha 4). Por outro lado, ao analisar o padrão eletroforético das proteínas virais do antígeno viral do ELISA, observamos que o tratamento realizado com SDS $0,1 \%$ não altera praticamente o perfil protéico do vírus (Linhas 3 e 4). Nessa figura, também se apresenta comparativamente o perfil de proteínas de MSC sem infectar (Linha 5).

\section{Detecção de anticorpos para CAEV Técnica de IDGA}

$\mathrm{Na}$ detecção de anticorpos contra o CAEV, observou-se que, das 343 amostras analisadas por IDGA, essa técnica detectou 30 (8,75\%) amostras positivas e $313(91,25 \%)$ negativas.

\section{Técnica imunoenzimática: ELISA indireto}

A detecção de anticorpos anti - CAEV nas 343 amostras analisadas pela técnica ELISA indireto, mostrou que72 $(21 \%)$ foram positivas e $271(79 \%)$ foram negativas.

Comparação das técnicas de ELISA indireto e

\section{$\underline{\text { IDGA }}$}

A técnica ELISA indireto mostrou uma maior sensibilidade a respeito da técnica de referencia atual IDGA (TABELA 2). O número de soros positivos para o CAEV detectados pela técnica ELISA foi maior (72/313) que o detectado pela técnica de referência IDGA (30/ 313). Teve divergência nos resultados em apenas 8 amostras, as quais foram positivas pela técnica IDGA e negativas pelo teste ELISA.

Ao ser comparado o teste ELISA indireto com a técnica de IDGA, que é o padrão ouro, o teste ELISA apresentou uma diferença significativa $\left(\chi^{2} ; \mathrm{p}<0,05\right)$, mostrando $73,3 \%$ de sensibilidade e $84 \%$ de especificidade, com índice fraco de concordância entre as técnicas (índice Kappa =0,35) (Tabela 2).

Detecção precoce de anticorpos pelo método de ELISA indireto

No Quadro 1, mostra-se o acompanhamento de um rebanho caprino no município de Feira de Santana (BA) pelo período de dois anos (com até 3 colheitas de soro em intervalos de 10 e 11 meses). Nos 13 caprinos avaliados durante esse período de colheita, nos animais A, B, C, E, G, foi possível a detecção precoce de anticorpos pelo teste ELISA já que a soroconversão nesses animais, segundo a técnica de IDGA, aconteceu quase um ano depois (animais C, E, G) e ainda em alguns animais (A e B) não foi possível detectar a soroconversão.

\section{DISCUSSÃO}

O diagnóstico sorológico de animais infectados pelo CAEV é difícil, considerandose que alguns animais podem apresentar baixos títulos de anticorpos, soroconversão tardia, ou ainda reações intermitentes de soropositividade e soronegatividade, exigindo-se, assim, provas sensíveis. (EAST et al., 1993; PHELPS; SMITH, 1993; CLAVIJO; THORSEN, 1995; HANSON; HYDBRING; OLSSON, 1996). A IDGA - técnica de referência para o diagnóstico do CAEV - é uma prova de baixa sensibilidade, mas é um teste amplamente utilizado e de referência no Brasil no diagnóstico de infecções 
Tabela 1. Municípios do Estado da Bahia onde foram coletadas amostras de sangue de caprinos.

\begin{tabular}{lclc}
\hline Município & Quantidade de animais & Município & Quantidade de animais \\
\hline Camaçari & 14 animais & Guanambi & 25 animais \\
Camaçari 2 & 8 animais & Central 1 & 4 animais \\
Bonfim de Feira & 31 animais & Central 2 & 8 animais \\
Feira de Santana 1 & 21 animais & Ipirá 1 & 21 animais \\
Feira de Santana 2 & 20 animais & Ipirá 2 & 20 animais \\
Feira de Santana 3 & 30 animais & Baixa Grande & 98 animais \\
Feira de Santana 4 & 31 animais & Itaberaba & 12 animais \\
TOTAL & 155 animais & TOTAL & 188 animais \\
\hline
\end{tabular}

Figura 1. Perfil eletroforético das proteínas virais do CAEV.

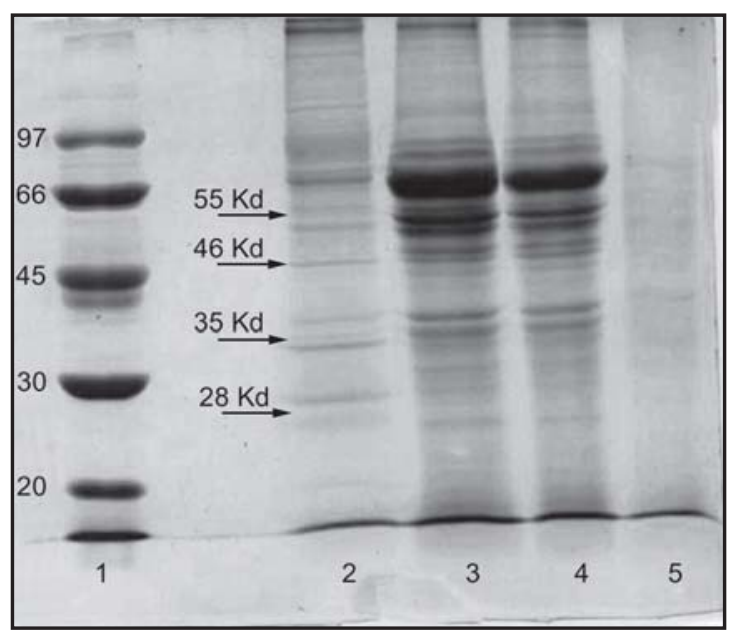

Notas: Eletroforese em gel de poliacrilamida de gradiente (5 15\%); (SDS - PAGE) do CAEV. 1) Marcador de peso molecular (Amersham); 2) CAEV Ultracentrifugado (FONTES et al., 2005); 3) Células MSC infectadas tratadas com SDS; 4) Células MSC infectadas sem tratamento com SDS; 5) Célula MSC sem infectar. As setas indicam o peso molecular aproximado das proteínas virais.

por este Lentivírus (KNOWLES JR et al., 1994; ABREU et al., 1998).

Este trabalho descreve um método simples e rápido de produção de antígeno para um teste ELISA indireto, usado no sorodiagnóstico do CAEV, obtido de culturas de células de MSC tratadas com SDS, o que não requer uma manipulação complexa ou o uso de equipamentos sofisticados. Esse antígeno viral conseguiu detectar anticorpos em animais que tinham sido negativos pela técnica de IDGA, e ainda detectou precocemente a infecção em animais repetidamente soronegativos em pelo menos duas amostras consecutivas, em intervalos de 1 ano.
Tabela 2. Comparação dos resultados obtidos em amostras de soros pelas técnicas IDGA e ELISA indireto.

\begin{tabular}{lccc}
\hline & IDGA + & IDGA- & TOTAL \\
\hline ELISA + & 22 & 50 & 72 \\
ELISA - & 8 & 263 & 271 \\
TOTAL & 30 & 313 & 343 \\
\hline
\end{tabular}

Notas: Os resultados foram expressos como positivos $(+)$ e negativos $(-)$. sensibilidade $=73,3 \%$; especificidade $=84 \%$; índice Kappa $=0,35$; fraca concordância entre as técnicas.

Existem relatos do uso do SDS para tratamento de antígenos utilizados no teste ELISA com o vírus Maedi-Visna, um retrovírus antigenicamente relacionado (HECKERT et al., 1992; SCHALIE et al., 1994; SIMARD et al., 2001). O SDS é um detergente iônico que, em baixas concentraçôes, ajuda a expor epítopos ou determinadas proteínas antigênicas para melhorar o reconhecimento entre antígenoanticorpo, o que, por conseqüência, aumenta a sensibilidade na detecção de anticorpos. Esse tratamento com SDS aparentemente não alterou o perfil protéico viral de CAEV, mantendo-se similar ao perfil-padrão, mas contribuiu, segundo os diferentes ensaios realizados, para aumentar a sensibilidade na relação entre antígeno viral e antígeno celular,

O teste ELISA é uma técnica de maior sensibilidade que a IDGA, devido ao mecanismo de interação antígeno-anticorpo que ambas envolvem. Enquanto os testes imunoenzimáticos requerem a interação de apenas um epítopo por anticorpo para se obter um resultado positivo, o teste de IDGA requer a interação de vários epítopos por reação. Além disso, alterações 
Quadro 1. Acompanhamento sorológico de 13 caprinos de uma mesma propriedade pelo período de 2 anos, Bahia.

\begin{tabular}{|c|c|c|c|}
\hline Animais & Data/Colheita & IDGA & ELISA \\
\hline \multirow[t]{2}{*}{ A } & $08 / 09 / 2005$ & - & + \\
\hline & $17 / 07 / 2006$ & - & + \\
\hline \multirow[t]{2}{*}{ B } & $08 / 09 / 2005$ & - & + \\
\hline & $17 / 07 / 2006$ & - & + \\
\hline \multirow[t]{3}{*}{$\mathrm{C}$} & $08 / 09 / 2005$ & - & + \\
\hline & $17 / 07 / 2006$ & - & + \\
\hline & $20 / 06 / 2007$ & + & + \\
\hline \multirow[t]{2}{*}{$\mathrm{D}$} & $08 / 09 / 2005$ & - & - \\
\hline & $17 / 07 / 2006$ & - & - \\
\hline \multirow[t]{3}{*}{$\mathrm{E}$} & $08 / 09 / 2005$ & - & - \\
\hline & $17 / 07 / 2006$ & - & + \\
\hline & $20 / 06 / 2007$ & + & + \\
\hline \multirow[t]{2}{*}{$\mathrm{F}$} & $17 / 07 / 2006$ & - & - \\
\hline & $20 / 06 / 2007$ & - & - \\
\hline \multirow[t]{2}{*}{ G } & $17 / 07 / 2006$ & - & + \\
\hline & $20 / 06 / 2007$ & + & + \\
\hline \multirow[t]{2}{*}{$\mathrm{H}$} & $17 / 07 / 2006$ & - & - \\
\hline & $20 / 06 / 2007$ & - & - \\
\hline \multirow[t]{2}{*}{ I } & $17 / 07 / 2006$ & - & - \\
\hline & $20 / 06 / 2007$ & + & + \\
\hline \multirow[t]{2}{*}{$\mathrm{J}$} & $17 / 07 / 2006$ & - & - \\
\hline & $20 / 06 / 2007$ & - & - \\
\hline \multirow[t]{2}{*}{$\mathrm{K}$} & $17 / 07 / 2006$ & - & - \\
\hline & $20 / 06 / 2007$ & - & - \\
\hline \multirow[t]{2}{*}{$\mathrm{L}$} & $17 / 07 / 2006$ & - & - \\
\hline & $20 / 06 / 2007$ & - & - \\
\hline \multirow[t]{2}{*}{ M } & $17 / 07 / 2006$ & - & - \\
\hline & $20 / 06 / 2007$ & - & - \\
\hline
\end{tabular}

Nota: os resultados foram expressos como positivos (+) e negativos (-).

antigênicas nas proteínas e glicoproteínas também podem influenciar a sensibilidade dos testes (CELER JR. et al., 1998; REISCHAK; RAVAZZOLO; MOOJEN, 2002).

Portanto, este trabalho relata a produção de um antígeno viral de fácil obtenção, com a utilização de uma metodologia simples e de baixo custo, a qual, empregada em um teste ELISA indireto, permitiu a obtenção de um teste sensível, específico e de detecção precoce de anticorpos para CAEV em caprinos.

\section{CONCLUSÕES}

O antígeno viral obtido de células de MSC infectadas com CAEV pode ser utilizado para detecção de anticorpos para o vírus da CAE em um teste ELISA indireto, mostrando-se mais sensível que a atual técnica IDGA.

\section{Viral antigen production for the sorodiagnostic of the caprine arthritis - encephalitis virus using one test imunoenzimatic (ELISA)}




\section{Abstract}

Caprine-arthritis encephalitis virus (CAEV) is a small ruminant lentivirus, which causes chronicle and progressive illness characterized by encephalomyelitis, mastitis, pneumonia and arthritis. The diagnosis is based on the detection of antibodies against virus through Agar Gel immunodifussion test (AGIDT), a reference technique for CAEV. The objective of this work was to produce CAEV antigen from infected cell culture of goat sinovial membrane to use in a enzyme-linked immunosorbent assay (ELISA) test. The pellet from infected cells was submitted to a treatment with SDS $0.1 \%$ for possible use as viral antigen in ELISA test. A total of 343 goat serum samples have been tested by indirect ELISA test and compared to AGIDT. The number of positives to ELISA test and AGIDT was 72 (21\%) and 30 (8\%), respectively. Moreover, the ELISA test detected an early seroconversion in 5 animals from a group of 13 goats during two years of continuous sampling. Relative to those tests, ELISA had a point estimate of 73, 3\% sensitivity and $84 \%$ specificity. ELISA test using a viral antigen above mentioned is shown to be effective, low-cost and sensitive for serological detection of antibodies to CAEV.

Keywords: Caprine arthritis-encephalitis virus - Diagnosis; ELISA.

\section{REFERÊNCIAS}

ABREU, S.R.O. et al. Produção de antígeno nucleoproteíco do vírus da artrite: encefalite caprina e comparação com o do vírus MaediVisna para utilização em teste de imunodifusão em Agar gel. Pesq. Vet. Bras., Rio de Janeiro, v.18, n.2, p.57-60, 1998.

CALLADO, A.K.C.; CASTRO, R.S.; TEIXEIRA, M.F. da S. Lentivírus de pequenos ruminantes (CAEV e Maedi-Visna): revisão e perspectivas. Pesq. Vet. Bras., Rio de Janeiro, v.21, p.87-97, 2001.

CELER JR, V. et al. Serologic diagnosis of ovine lentiviruses by whole vírus ELISA and AGID test. Zentralbl. Veterinarmed. B, v.45, p.183-188, 1998.

CLAVIJO, A.; THORSEN, J. Chemiluminescent detection of caprine arthritis-encephalitis virus with a PCR - generated single stranded nonradiolabelled probe. Vet. Microbiol., Amsterdam, v.43, p.295-305, 1995.

EAST, N.E. et al. Modes of trasmission of caprine arthritis-encephalitis virus infection. Small Rumin. Res., Amsterdam, v.10, p.251-262, 1993.

FONTES, L.V.Q. et al. Precipitacion of bovine rotavirus by polyethylene glycol (PEG) and application to produce polyclonal and monoclonal antibodies. J. Virol. Methods, Amsterdam, v.123, p.147-153, 2005.
GARFIN, D.E. One-dimensional gel electrophoresis. In:DEUTSCHER, M.P. (Ed.). Guide to protein purification. San Diego: Academic Press, 1990. p.425-440. (Methods in Enzymology, v.182).

HANSON, J.; HYDBRING, E.; OLSSON, K. A long term study: goats naturally infected with caprine artrhritis-encephalitis virus. Acta Vet. Scand., London, v.37, p.31-39, 1996.

HARKISS, G.D.; WATT, N.J. Lentivirus infections and their detection. Goat Vet. Soc. J., Cambridge, UK, v.11, n.1, p.19-25, 1990.

HECKERT, R.A. et al. Evaluation of an enzymelinked immunosorbent assay for the detection of antibodies to caprine arthritis-encephalitis virus in goat serum. Can. J. Vet. Res., Ottawa, v..56, p.237-241, 1992.

KNOWLES JR, D.P. et al. Evaluation of agar gel immunodifusion serology using caprine and ovine lentiviral antigens for detection of antibody to caprine arthritis-encephalitis virus. J. Clin. Microbiol., Washington, DC. v.32, p.243-245, 1994.

LAEMMLI, U.K. Cleavage of structural proteins during the assembly of the head of bacteriophage T4. Nature, London, v.227, p.680-685, 1970.

PHELPS, S.L.; SMITH, M.S. Caprine arthritis-encephalitis virus infection. J. Am. Vet. Med. Assoc., Schaumburg, v.203, n.12, p.1663-1668, 1993. 
REISCHAK, D.; RAVAZZOLO, A.P.; MOOJEN, V. Imunofluorescência utilizando isolados brasileiros no diagnóstico sorológico de infecção por lentivírus em caprinos. Pesq. Vet. Bras., Rio de Janeiro, v.22, p.7-12, 2002.

SCHALIE, J.V. et al. Evaluation of a Kinetic enzyme-linked immunosorbent assay for detection of caprine arthritis-encephalitis virusspecific antibodies. J. Vet. Diagn. Invest., Columbia, v.6, p.30-33, 1994.

SIMARD, C. et al. Simple and rapid method for production of whole-virus antigen for serodiagnosis of caprine athritis-encephalitis virus by enzime-linked immunosorbent assay. Clin. Diag. Lab. Immunol., Washington, DC, v.8, n.2, p.352-356, 2001.
THRUSFIELD, M. Diagnostic testing. In: Veterinary epidemiology. $2^{\text {nd }} . e d$. Edinburgh: Blackwell, 1997. p.280-282

TIGRE, D.M.; CAMPOS, G.S.; SARDI, S.I.. Isolamento e identificação do vírus da artrite-encefalite caprina a partir do cocultivo de células mononucleares do sangue com células de membrana sinovial de cabras. R. Ci. Méd. Biol., Salvador, v.5, p.100-108, 2006 .

VALLAT, B. Manual of standards for diagnostic test and vaccines for terrestrial animals. $5^{\text {th }}$. ed. Paris: Office International des Epizooties, 2004. Disponível em: <http://www.oie.int>. Acesso em: 3 maio 2008. 